\title{
DEL PAPEL A LAS TABLAS: EL PROCESO TRANSDUCTIVO DE CINCO HORAS CON MARIO DE DELIBES (NOVELA, VERSIONES, REPRESENTACIONES TEATRALES)
}

\author{
José R. VALles CALATRAVA \\ Universidad de Almería
}

\begin{abstract}
La finalidad de este estudio consiste en realizar un análisis comparativo entre la novela de Miguel Delibes Cinco horas con Mario (aparecida en 1966), sus dos versiones para teatro (realizadas en 1979 y 2001), y dos de las representaciones concretas respectivamente basadas en las anteriores (en el Teatro Marquina en diciembre de 1979 y en el Teatro Real Cinema en octubre de 2003). Se trata, pues, quede claro desde un principio, no de analizar una novela ni un texto dramático, sino de poner de manifiesto e interpretar las relaciones existentes, con respecto a una misma y común historia y a través del mismo camino de la adaptación, entre diversas obras que, aparte de sus lenguajes y procesos comunicativos distintos, se manifiestan diferentes no sólo en el ámbito textual o individual sino en el architextual o genérico.

Efectivamente, un primer aspecto del trabajo afecta a la conversión del texto novelístico en texto, o mejor pre-texto, teatral, es decir, a la adaptación de la novela de Delibes a la par como un antetexto y como una excusa para la representación espectacular. La adaptación, junto a otros procedimientos de reelaboración o reescritura textual que transforman un texto «original» o «de partida» en otro «resultante» o «final» (como, principalmente, la traducción o la hipertextualidad) forma parte, como es sabido, de los complejos procesos de retextualización de cualquier tipo que se conocen con el nombre de transducción (Dolezel, 1986; Schmidt, 1980; Valles y Álamo, 2002) o de transmodalización (Genette, 1982). La dramatización de la novela constituye, pues, en primera instancia, una transmutación genérica, una transducción architextual, que afecta a la relación narrativa/drama, de obligado tratamiento.
\end{abstract}

Pero, en segundo término, el presente análisis debe abordar asimismo

Rlit, LXVI, 132 (2004), 485-502 
las similitudes y diferencias particulares existentes entre las distintas representaciones espectaculares (1979 y 2003) basadas en las dos versiones teatrales (1979 y 2001), también firmadas por Delibes entre otros, y de todas con respecto a la originaria creación novelesca de Cinco horas con Mario (1966). Esta dimensión concierne, pues, a las conexiones puramente textuales, a las relaciones individuales dadas entre aquello que Talens (1986: 21-22) denominaba «espacios textuales».

Estos dos diversos y distinguibles flancos del análisis serán, no obstante, conjuntamente abordados en la estructura de este trabajo, que, en coherencia con el objetivo antes expuesto, metodológicamente dará cuenta primero de forma breve de algunas de las claves de la obra narrativa de Delibes que la enfatizan como texto virtualmente idóneo para el teatro, pasará después a referirse a sus dos versiones dramáticas concretas, incidiendo a la par en sus relaciones internas y con respecto al texto novelesco originario, y finalizará examinando las especificidades y diferencias de las distintas representaciones escénicas basadas en las anteriores.

\section{LA ADAPTABILIDAD: POTENCIALIDADES TEATRALES DE LA NOVELA}

No es pretensión de este estudio centrarse, no ya en la trayectoria novelística de Delibes, sino ni siquiera en una obra tan compleja técnica y significativamente aunque tan simple estructuralmente, tan representativa del segundo ciclo del autor vallisoletano y aun de toda la etapa de la renovación experimental de la narrativa española contemporánea, tan discutida y evaluada por la crítica aunque de forma tan extensa, tan diversa y hasta tan polémica, como es Cinco horas con Mario. Al contrario, se trata aquí, de acuerdo con nuestro objetivo y como se ha anticipado, de incidir en algunos de los aspectos que la enaltecen como texto novelesco potencialmente idóneo para su escenificación, como texto novelesco caracterizado por una gran «adaptabilidad», en definición del único productor de sus dos montajes teatrales, José Sámano (Europa Press, 18-03-02).

En general, la «adaptabilidad» teatral de los textos narrativos, con no ser absolutamente extraña a la condición del género, sobre todo en las novelas de conflicto o de tesis y todavía más en las denominadas «novelas escenificadas»-que están marcadas por un narrador ausente (Chatman, 1978) y por un desarrollo discursivo enteramente dialogado, por la activación exclusiva de un modo dramático que denominaba Lubbock showing (Valles-Álamo, 2002: 318-319 y 554)-, es mucho más común sin embargo con respecto al cine, a las series televisivas o al cómic, esto es, con respecto a los medios primordialmente narrativos e icónicos a la vez.

No obstante, el caso de la obra de Delibes es muy especial en lo referente a sus adaptaciones. De una parte, porque la película de 1981 Fun- 
ción de noche, también dirigida, como las representaciones teatrales, por Josefina Molina, con guión de esta y Sámano y protagonizada por Lola Herrera, no sólo es posterior a la versión teatral de 1979 sino también bastante distinta, aunque se base en ella más que en el relato. De otro lado, porque la propia novela posee de suyo numerosos - digamos - «valores teatrales virtuales» como, entre otros, su estructura trimembre, su organización argumental, su tematización de un permanente y único conflicto, el interés y variedad de su historia, la irrelevancia del narrador y su diseño primordial como monólogo, la simplicidad de sus componentes temporal y espacial. Finalmente, porque la misma Productora de Sámano, SABRE FILMS, ha acometido el intento de adaptar al teatro una trilogía de la obra novelesca de Delibes, formada por la novela que examinamos, por Las guerras de nuestros antepasados y por La hoja roja, cuyas relaciones narrativo-dramáticas han sido estudiadas por Vega Martín (1995).

El relato, abierto con la reproducción de una esquela que informa de la muerte de Mario, contiene una secuencia dialogada inicial y otra final que enmarcan a 27 capítulos intermedios. Estos, que constituyen el centro tanto estructural como temático de la historia, se abren con fragmentos de la Biblia subrayados por Mario que permiten a su viuda, Carmen, un ejercicio rememorativo de diversos aspectos de su vida en común donde se manifiesta una contraposición total de las perspectivas de ambos con respecto a todas las dimensiones, intra y extrapersonales, de su relación. De este modo, con los materiales selectivos y parciales proporcionados por la memoria y con el instrumento del pensamiento abordando indistintamente unos y otros asuntos, se teje en forma monológica - como monólogo interior directo según Anderson (cfr. G y A. Gullón, 1974), monólogo autónomo según Cohn (1978), discurso inmediato según Genette (1972) o monólogo autorreflexivo según Beltrán (1992) - y ante el cadáver del marido, una evocación mental cuyo contenido dialógico se manifiesta en todos los órdenes: el uso alternante de la primera y segunda persona con planteamiento autobiográfico y autorreflexivo a la vez (Garrido, 2000: 169-170), la reproducción en la voz de Carmen de los discursos y actos de una y otro, las diferentes y hasta opuestas visiones de ambos de las cuestiones relativas al ámbito privado (económicas, familiares, sexuales...) o público (sociales, políticas, laborales, religiosas...), es decir, no sólo su desintonía sino su contraposición.

Pese a la reconocida importancia de la obra en la literatura española contemporánea, la misma, como demuestra Medina-Bocos (1987: 111-120) al abordar sus lazos intertextuales, no es absolutamente original ni en su historia, ni en su técnica, ni en su forma. Se han observado así relaciones temáticas con dramas como Quién teme a Virginia Woolf de Albee y, sobre todo, Antes del desayuno de O'Neill, y con novelas hispánicas como Algo pasa en la calle de Elena Quiroga o Equipaje de amor para la tierra 
de Rodrigo Rubio; Sobejano (1981: 93) indica los vínculos con El Jarama o Entre visillos en cuanto a la reproducción del lenguaje coloquial; autotextualmente, con respecto a la propia obra de Delibes, Agnes Gullón (1980: 47) comenta las similitudes formales y estructurales con Las ratas y Darío Villanueva (1977: 243-244) las establece con El camino, siendo particularmente resaltables, en cuanto al uso de la técnica del monólogo, las dadas con algunos cuentos anteriores recogidos en La mortaja y con la novela posterior Parábola del náufrago.

Tres son, a mi entender, los grandes rasgos de teatralidad virtual de esta novela.

a) Un primer factor de potencialidad teatral de la obra viene dado por la reducción y condensación de los componentes estructurales de la historia. Un espacio cerrado y limitado, ceñido a una casa y a un despacho que funciona como cámara mortúoria. Un tiempo que enfatiza las cinco horas de velatorio del cadáver y monólogo de Menchu entre el anochecer y el amanecer. Muy pocos personajes relevantes (Carmen y su hijo, Mario) junto a diversos actuantes terciarios o figurantes. Acontecimientos limitados a las conversaciones o rememoraciones realizadas durante la vela del difunto catedrático. En realidad, todos estos elementos tan simplemente esbozados se encuentran anunciados, y más concentrados incluso, en la esquela mortuoria que abre la obra, a modo de cornisa o friso que vaticina y sintetiza lo que sigue: ahí figuran la dirección de la casa mortuoria, el día de la muerte y el límite temporal de la historia marcado por la misa y conducción del cadáver, los principales agentes en su condición de familiares del muerto y el mismo hecho central del velatorio.

b) El segundo elemento claro de adaptabilidad teatral lo proporciona la organización formal y la estructura de intensidad o tensión de la historia narrada. Una acción diversamente organizada pero mononuclear en cuanto a la existencia de un acontecimiento central (el velatorio) sobre el que gira en diversos órdenes y formas el discurso principal (la evocación de la vida en común). Una organización formal trimembre del discurso, con una secuencia inicial y otra final con presencia de elementos narrativos y dialogados y una extensa secuencia media, conformada por 27 distintas evocaciones suscitadas por diversos fragmentos bíblicos, que constituye el ejercicio turbio y deslizante del recuerdo de Carmen. Una estructura de intensidad narrativa en el que la ordenación de la acción en ascenso y en descenso, con su clímax intermedio, se relaciona, a tenor de lo diseñado en la pirámide de Freytag (Valles-Álamo, 2002: 597) y como bien ha observado Sobejano (1981: 131), con la organización de la acción unitaria en las tres fases de la exposición memorativa, la complicación acusatorio-defensiva y la solución confesional, coincidentes si se quiere, en términos de Bremond (1973: 131-133), con la propia lógica secuencial del relato. 
c) El tercer y último gran componente de teatralidad virtual de la novela de Delibes reside a nuestro entender en el gran peso e interés de la historia frente a la función cuantitativa y cualitativamente poco relevante del narrador heterodiegético con focalización omnisciente que se advierte al inicio y al final y que se elide durante todo el monólogo interior de Carmen aunque haciendo depender lógicamente el mismo de su posición de sabiduría total. La escasa relevancia del narrador coincide con la naturaleza genérica del drama, que elimina al relator para mostrar directamente el relato de la historia, y aquí, además, como indica Pilar Celma (2003: 23), permite subrayar el papel parcial y limitado de la visión de un personaje en coincidencia con las propias limitaciones de la España provinciana de mediados de los años sesenta, a la vez que, haciendo gravitar toda la obra sobre ese personaje y su discurso, posibilita un papel actoral teatral enormemente largo y difícil pero estelar y atractivo.

\section{LAS VERSIONES TEATRALES DE 1979 Y 2001 FRENTE A LA NOVELA}

La primera versión dramática, de 1979, está firmada por Miguel Delibes, Santiago Paredes, Josefina Molina y José Sámano, fue publicada por EspasaCalpe en 1981 y originó una primera representación espectacular que se produjo el 26 de noviembre de 1979 en el Teatro Marquina de Madrid. La segunda es de 2001 y su texto, inédito, de 48 folios, ha sido realizado por casi los mismos autores -salvo Paredes-, generando su estreno escénico en el Teatro Calderón de Valladolid el 6 de octubre de 2001.

Ambas versiones comparten varios aspectos: unos mismos autores y una misma novela de base, unos mismos creadores y una misma historia y lenguaje básicos. No obstante, como es lógico, entre el texto novelesco y el texto escrito de las adaptaciones - al igual que entre estas últimas también-, se producen una serie de mutaciones o cambios que responden a necesidades de la transducción, requerimientos de dramatización o conveniencias de adecuación histórica y lingüística.

\subsection{Alteraciones textuales de las versiones teatrales}

Cuantitativa y cualitativamente, sin duda el fenómeno más interesante es el de las supresiones. La finalidad representativa y la necesaria adecuación a los nuevos momentos históricos ha reducido muy sustancialmente no sólo las secuencias inicial y final, prologal y epilogal, sino el propio monólogo de Carmen, tanto en los temas abordados y personajes aludidos, cuanto en estructura y duración. En las dos versiones, que son muy parecidas, se opera con un tiempo de la representación que oscila en torno a 
la hora y media y que contrae el mucho más extenso tiempo de la lectura. También en ambas se anula la fragmentación capitular de la novela para unificar la reflexión de Carmen. Se suprimen las alusiones a muchos seres de función referencial y casi irrelevante (los poetas Canido y Borrés, el portero, algunos contertulios de Mario, la intelectual Esther y su esposo, los locos y el barrendero...). Desaparecen absolutamente todos los segmentos bíblicos que inician capítulo y nuevo tercio de reflexión, y sólo alguna frase de Carmen o la recomendación del hojeo de la Biblia en las acotaciones aluden a su importante papel en la obra. Se eliminan muchísimos fragmentos evocativos de Carmen, siempre los más superfluos y menos relevantes con respecto al conflicto y a la caracterización de los dos personajes básicos, pero están prácticamente todos los acontecimientos fundamentales, salvo la «Memoria» con que el suegro de Mario le ayudó en sus oposiciones: aunque en realidad hay textos de prácticamente todos los 27 capítulos novelescos, destacan los procedentes de los números I, II, VI, VII, XV, XIX, XXIV y XXVII, esto es, de los temas referidos a valores sentimentales, dinero, caridad, guerra, autoridad, soledad, enfermedad y complejo de culpa (Sobejano, 1981: 108-129).

Son muy frecuentes, aunque de muy escasa relevancia, las modificaciones textuales, cuya función primordial es la de actualizar el texto de forma lingüística (usar los presentes verbales simultáneos en escena en lugar de los pretéritos narrativos propios de un relato ulterior, emplear como eufemismo asistenta por criada, dar más fuerza con la expresión «juventud podrida» que «perdida»), de modo histórico (introducir Hacienda en la reflexión de Carmen sobre la caridad, que Eliseo piense que Carmen no es una Venus sino una Sofía Loren) e incluso de manera metalingüística (informar en breves palabras de Carmen de la pluralidad de alusiones al trabajo periodístico y a las tres novelas de Mario o atribuir frases de personajes suprimidos en el drama a otros presentes, como la del diputado Armando a Oyarzun).

En cambio, son más extrañas y también más irrelevantes las adiciones: una frase inicial dicha por Carmen sobre la lectura de la Biblia por Mario que viene a sustituir a los párrafos bíblicos iniciales de la novela, el acercamiento final del adulterio de Carmen con Paco al «lunes» antes de la muerte, alguna palabra suelta y nueva y poco más.

En este apartado y en cambio, interesa señalar el mantenimiento y permanencia en las versiones teatrales del diseño lingüístico básico de ese largo monólogo reflexivo-rememorativo de Carmen en la novela original; han sido muy numerosos los críticos (Gullón, 1980; Montero, 1968; Morán, 1971; Sobejano, 1981) que han resaltado sus principales características: el caos expositivo y la abundancia de cláusulas largas y oraciones subordinadas, la estructura reiterativa (repetición de epítetos invocativos denominando a Mario - algunos de ellos despreciativos-, repetición de oraciones inicia- 
das por «que», repetición de negaciones y de vocativos), el coloquialismo, la profusión de modismos y frases hechas, la presencia de términos de la jerga madrileña y del lenguaje religioso, etc.

\subsection{Diferencias textuales entre las versiones dramáticas}

Mucho más interesantes son las alteraciones existentes entre las dos versiones de 1979 y 2001, si bien ambas siguen siendo bastante o muy parecidas.

Lo más significativo es la eliminación de todas las acotaciones contenidas en el largo parlamento de Carmen, así como casi todas las de la escena final de Carmen y su hijo: estas instrucciones escénicas, que en su mayor parte estaban referidas a aspectos proxémicos, cinésicos y tonales, se eliden totalmente, dejando estas cuestiones al arbitrio de directora y actriz y haciendo desaparecer a la par algunos de los toques excesivamente trágicos y efectistas de la primera versión. Pero, de este modo también, se suprime toda referencia y alusión, aunque fuera leve y en calidad de accesorio a la Biblia (no ocurre así en la representación, en la que Lola Herrera sí la lleva en las manos varias veces), que sin embargo, desde mi perspectiva, tanta importancia tiene como base interpretativa doble que sustenta las diferentes posiciones morales, religiosas y humanas de los esposos en la obra.

El otro aspecto importante en las reducciones consiste en la eliminación de párrafos enteros: el de los nombres de los hijos, el extenso del fusilamiento del hermano de Mario, el breve de la comparación de Cristo con los rojos, el más largo sobre Cáritas, el de las ayudas a delincuentes comunes o el temor a la llegada de la policía.

Algunas escasas y poco trascendentes modificaciones y adiciones tienden a aproximar histórica y lingüísticamente el texto al nuevo momento histórico de su recepción: admitir obreros en Alemania y no en el extranjero, decir que la mujer prefiera atropello a humillación, aludir al protestantismo, plantear qué diría el servicio, etc; sin embargo, aunque algunas otras actualizaciones convenientes, como la de subir la renta de un piso de 700 pesetas, se han escapado en ambas versiones. Hay, no obstante, otras adiciones que sí son mucho más relevantes y que también tienen pretensión de actualización histórica del texto; se trata de párrafos enteros sobre el sueño de viajar y tomar aviones, sobre la no realización del acto sexual avanzado el embarazo, sobre la música clásica con que se dormía Borja, sobre lo peligroso del pensamiento, sobre los negros como emigrantes, sobre la corrupción y sobre la sospecha de relaciones de Mario con Encarna.

Pero los cambios lingüísticos y discursivos entre novela y adaptaciones no se limitan a tales alteraciones textuales sino que hay otras requeridas 
por la propia transgenerización. En la medida en que el teatro es simulacro escénico de una historia y representación orientada al espectáculo, otros elementos de carácter gestual, tonal, lumínico, sonoro, proxémico, etc. (Bettetini, 1978; Bobes, 1987; Pavis, 1980) se integran con el lenguaje verbal para cosignificar y comunicar la historia representada. En ese sentido y al margen de la representación escénica concreta, cabe aludir a las instrucciones al respecto suministradas por los textos de las dos versiones adaptativas. Las acotaciones de la primera y segunda versión coinciden prácticamente en la descripción inicial de la subida del telón, la de presentación de la cámara mortuoria que abre el monólogo de Carmen, la de la entrada del hijo en la escena final y la de cierre: se trata de las instrucciones más completas sobre luz, música, decorado, accesorios y salida y entrada de actores. En cambio, el resto de acotaciones presentes en la primera versión y referidas a la actuación de Carmen, que eran numerosísimas y breves y sobre todo afectaban a posición, movimiento, gesto y tono, se suprimen absolutamente en la segunda, quedando tan solo una alusiva al tarareo de una canción y otra concerniente al sonido de cinco campanadas; esto es altamente significativo porque, de este modo, se confía directamente al arbitrio y a la experiencia de directora y actriz - las mismas que ya habían puesto en marcha las representaciones de la primera versión - todo el trabajo puramente representativo, actoral.

En suma, la versión de 2001 altera la de 1979 en varias direcciones que por ahora me limito simplemente a enumerar: en primer lugar, se presenta en cuanto a la interpretación una versión menos simbólica y trágica, menos rígida y efectista; en segundo término, con la supresión de fragmentos en su mayoría alusivos a la Biblia o la religión y a la Guerra Civil o la situación política y con la entrada de textos referidos a la inmigración, el viaje o la corrupción se adecúa históricamente la versión al nuevo - digamos- «horizonte de expectativas»; en tercera instancia y a través de lo anterior, se consigue presentar asimismo una historia de las relaciones de Mario y Menchu menos cargada social y políticamente y más ceñida a lo amatorio y vital, menos preocupada por reproducir la visión de la pequeño-burguesía franquista que resaltaba Monleón (1979: 53) y más centrada en el desamor conyugal a que se refería Morán (1982: 48-49), más atenta ahora al ámbito de lo privado que de lo público y de lo humano que de lo sociopolítico. José Sámano, el productor, resume sus diferencias afirmando que ahora se muestra un desencuentro más humano y menos político (vid. Efe, 10-9-03); Lola Herrera, la actriz principal, señala el menor dolor y crispación y mayor ligereza y atino que se observa en la última versión con respecto a la anterior, así como su menor padecimiento y mayor disfrute actual al representar la obra (vid. Europa Press, 18-03-02). 
3. LAS REPRESENTACIONES TEATRALES DE 1979 Y 2003 FRENTE A NOVELA Y ADAPTACIONES

La obra teatral basada en la primera versión, que se estrenó el 26 de noviembre de 1979 en el Teatro Marquina de Madrid como se ha dicho, se mantuvo, aunque de forma interrumpida, durante diez años en cartelera, repitiendo en diversas ciudades españolas, y en su trayectoria escénica sobresale, como anécdota bien conocida, el desmayo de la actriz principal, Lola Herrera, sufrido el 4 de marzo de 1980 en la primera representación dada en el desaparecido Teatro Barcelona de la capital catalana.

La segunda adaptación, que inició su andadura como espectáculo en el Teatro Calderón de Valladolid el 6 de octubre de 2001 (vid. El Mundo, 4-12-01), efectuó a partir de entonces una gira de varios meses por distintas ciudades españolas y se mostró en el Teatro Real Cinema de Madrid a partir de septiembre de 2003.

Ambas creaciones comparten la misma directora (Josefina Molina), el mismo productor (José Sámano), el mismo escenógrafo (Rafael Palmero), la misma música (un tema basado en «La mala muerte» de Aute), casi los mismos autores (a excepción de Paredes en la segunda) y la misma actriz principal (Lola Herrera). Varía el acompañante (Jorge de Juan en la primera ocasión y Pablo Rodríguez en la última) y cambian también la iluminación (Francisco Fontanals/Juan Gómez Cornejo) y la dirección de producción (Margarita Kramer/Carmen San Román). Todos estos factores, además del ya examinado parecido de las dos versiones escritas, demuestran claramente la gran similitud de ambas adaptaciones.

\subsection{Diferencias en los procesos comunicativos extra e intratextuales}

Desde un punto de vista extratextual, los procesos pragmático-comunicativos de la novela y el teatro son completamente distintos, lo que provoca diversas y trascendentes implicaciones que cabe mencionar aquí. Pese a que cada una de las representaciones que actualizan cada adaptación constituya un texto espectacular distinto (y mi análisis parte de mis concretas visiones de la obra citadas en la Bibliografía), todas ellas de un lado y ambas adaptaciones de otro comparten también su inserción en un mismo modelo comunicativo, que cabe diferenciar del circuito propio de la narrativa escrita.

Efectivamente, la novela Cinco horas con Mario se sitúa dentro de un sistema comunicativo presidido por la «escritura», donde a unos característicos elementos técnicos y comerciales (imprenta, infoedición, editoriales, libros, etc.) así como físicos (escritura frente a lectura, luz y silencio, 
lejanía espaciotemporal, proceso diferido o «in absentia»...) se une un esquema rígido y unidireccional de flujo de información narrativa, dos instancias comunicadas que normalmente coinciden con dos individuos físicos y un producto textual u objeto narrativo -el libro, como prototextofijado, acotado, perdurable y multirreproducible.

Las representaciones de esa obra, más allá de las versiones dramáticas, se ubican al contrario en un modelo comunicativo, más complejo (Bobes, 1987: 31), que cabría denominar de «espectacular», más cercano incluso a la oralidad, que posee sus especificidades en cuanto a la integración de los elementos técnicos y comerciales (luz y sonido, maquinaria, sala, entrada, etc.) y de los aspectos físicos y materiales (recinto, escenario frente a sillón, oscuridad y silencio, coincidencia espacial y temporal, proceso «in praesentia») y que actualiza asimismo un esquema en el que las dos instancias comunicadas son normalmente múltiples y colectivas y poseen denominaciones profesionales específicas (director, actores, escenografía, compañía, productor «versus» público o espectadores) y donde el producto textual, consistente en una representación espectacular, se muestra singular e irreproducible, perecedero y no acotado.

El respectivo ajuste de los dos textos genéricos de Cinco horas con Mario, el novelesco y los teatrales, a sus sistemas comunicativos propios constituye una implicación pragmática que genera efectos intratextuales diversos y que se relaciona con los fenómenos ya vistos de los cambios discursivos por supresión, modificación o adición. Con el primero, la supresión, se vinculan, por ejemplo, la reducción textual, que opera en las adaptaciones escénicas limitando la mayor extensión de la novela y enfatizando sus centros de interés, y la abreviación durativa, que limita a aproximadamente hora y media el tiempo real de la representación frente a la mucho mayor duración del tiempo de la lectura. Con las modificaciones y las adiciones conectan los convenientes cambios lingüísticos de redacción y las necesarias actualizaciones de la obra, ya citadas, que pretenden hacerla más comprensible o más cercana al momento histórico y al público.

Además, en lo concerniente ya a un ámbito comunicativo intratextual, la dramatización exige, respecto a la novela de base, el mantenimiento de la historia, pero también presentar miméticamente a los personajes en acción y hacer desaparecer el esquema comunicativo primario narradornarratario (Domínguez Caparrós, 2002: 137). Por eso, las secuencias inicial y final de la novela, donde el narrador heterodiegético y omnisciente mezcla su discurso y voz con las voces y discursos ajenos, se resuelven de otro modo, esta vez coincidente, en las dos teatralizaciones: con la presencia del intercambio de voces de ambiente y en off, en oscuridad y sobre el fondo de la gran esquela, al principio; con el diálogo escénico puro y directo- entre Carmen y su hijo, en la cámara mortuoria y con el escenario iluminado, al final. También se redefine por ello todo el cuerpo 
central y amplio de las dos adaptaciones: lo que en la novela acepta el narrador - sin interferir - que sea un discurso directo e inmediato del personaje pero impronunciado, un monólogo interior que piensa Carmen y que sólo existe como evocación que salta de uno a otro tema en el ámbito de su conciencia (pese a la interpelación final a que Mario le dé el perdón), en las representaciones sobre las tablas genera un soliloquio, un monólogo que sí es pronunciado, no tanto por la viuda como por la actriz, que carece de auditor real expreso aunque el marido muerto funciona como tal para la conciencia y el habla de Carmen y que cabría vincular a la tradición del monólogo teatral hesitante de ciertas obras del Siglo de Oro (Calderón) o contemporáneas (P. Handke, B. Wilson, etc.)

Pero ese soliloquio, además, funciona ahora, curiosamente sobre las tablas, como una narración, como un relato, reducido y analéptico, reflexivo y rememorativo, de toda la vida marital común en el que la actriz interpretante cuenta desde el yo lo hecho anteriormente por ella - Carmen-, por su marido - Mario - o - menos - por otros utilizando el pasado y las 3 personas gramaticales, aunque la frecuencia de microrrelatos donde se alude a Mario haya hecho a Buckley (1973: 136) hablar del uso de la técnica de la segunda persona. Por otro lado, esa vida marital común, esa historia de desamor o desencuentro conyugal (más politizada en texto y lecturas de críticos y espectadores en la primera adaptación, más humanizada o personalizada en la segunda), aunque está narrada con una sola voz, adquiere una estructura dialógica —en el sentido que le otorga al término Bajtín (1929) - puesto que mantiene permanentemente en escena la contraposición entre dos discursos, entre dos visiones y dos concepciones del mundo y la vida, y acaso por eso Alfonso Rey (1975: 181) haya planteado el funcionamiento real de la obra como más próximo al diálogo que al monólogo.

\subsection{Diferencias escénicas entre novela y representaciones}

Compartir de modo global la misma historia es justamente lo que marca la coincidencia entre obras pertenecientes a órdenes architextuales tan distintos como la narrativa y el drama. Sin embargo, la presencia general de los mismos hechos en los componentes estructurales de la historia narrativa y dramatizada no equivale a la identidad de su orden ni de su diseño discursivo, pues, como puede apreciarse en las acotaciones de las versiones escritas o en los distintos lenguajes que confluyen en las representaciones, exigencias específicas físicas, de técnica, de lenguaje y de extensión configuran escénicamente tales componentes de modo distinto a como lo hace la mediación narrativa. $\mathrm{O}$, dicho de otro modo y con García Barrientos (1991: 84), una Fábula o material mentalmente ordenado se 
organiza y representa en una acción dramática concreta que se manifiesta discursivamente en una Escenificación determinada - T = F, D, E- .

Ya hemos ido planteando algunas de las disimilitudes observadas entre la novela y ambas representaciones espectaculares que, de otro lado, son, como las versiones dramáticas escritas, muy parecidas aunque no exactas. El soliloquio, la forma de resolución de las escenas inicial y final, las alteraciones del original — básicamente por supresión-, la reducción de la cantidad de tiempo de lectura y espacio textual para la adecuación a la escena, el distinto proceso comunicativo, etc. son algunas de las diferencias ya mencionadas entre el texto novelesco y los espectaculares. No obstante, cabe afirmar que, en el campo de la acción y los acontecimientos, en la medida en que se trata de adaptaciones - relativamente- muy fidedignas y autorizadas y en que hay una coincidencia básica y general de la historia narrativa y la historia dramática, las dos representaciones de 1979 y 2003, pese a ligeras diferencias, sintonizan bien novela y adaptaciones en aspectos - ya citados al aludir a la adaptabilidad - como la inclusión de los sucesos narrativos más relevantes, la lógica secuencial, la estructura trimembre y la organización de la tensión o intensidad.

Hay, eso sí, tres importantes divergencias concernientes a nuestra forma de conocer los acontecimientos de la historia narrativa y dramática en las que conviene incidir. La primera se refiere a la mediación actoral, pues sobre las tablas la historia nos es contada, no por un narrador heterodiegético y omnisciente que deja que fluya libre y directamente el pensamiento de Carmen Sotillo durante la mayor parte del espacio textual, sino a través de una intermediaria - Lola Herrera-, de una actuante escénica que media entre personaje y receptor y asume ante el segundo la personalidad, actuación y voz del primero. La segunda se vincula con el modo directo, escénico y representativo, en que la historia se nos muestra, en que la historia se nos enseña y hace ver como acción patente y desarrollada sobre el escenario. La tercera conecta con nuestro papel de espectadores - o de público si se entiende colectivamente - antes que de lectores, y por ello con el aumento de relevancia del papel de la captación sensorial en detrimento del papel de la actividad imaginativa y la cooperación interpretativa.

La localización espacial consiste en la novela en distintos interiores sucesivos de una vivienda (vestíbulo, dormitorio, pasillo, despacho) que funcionan como casa y cámara mortuoria y que van siendo más o menos dibujados y configurados mediante el uso del lenguaje y la descripción: así, por ejemplo, la abertura de la ventana del despacho y la luz de la madrugada y los diversos ruidos de la calle iluminan y transforman el despacho en la secuencia final. Esas localizaciones se transforman en «ámbitos de actuación» distintos (Valles, 1999: 89-124), marcos espaciotemporales donde suceden cosas diversas, existiendo uno por cada una de las 
27 secuencias en que se fragmenta la acción y el pensamiento de Carmen más el de apertura y cierre.

Sin embargo, en ambas adaptaciones escénicas, no existe más emplazamiento situacional para toda la obra que un despacho convertido en cámara mortuoria y este mismo lugar ofrece tres ámbitos escénicos distintos: el de las escenas primera y última y el de una gran escena intermedia, que integra los 27 ámbitos actuacionales del relato y en la que, con larga duración y sin interrupción, se desarrolla todo el soliloquio de Lola Herrera. El mobiliario, siendo materialmente distinto, es de la misma naturaleza en ambas versiones y representaciones: a la izquierda, un sillón y una mesa con una silla y con escribanía, libros, termo y caja de tabaco, dos sillas violetas a la derecha y un «rectángulo prominente», también violeta, que simboliza el féretro y ocupa el centro del escenario. El decorado es asimismo muy similar: una caja violeta en perspectiva en el primer montaje, tres sucesivos marcos violetas algo asimétricos, que acentúan la sensación de interior, cerrazón y agobio, en el segundo. También coinciden los útiles empleados ocasionalmente por la actriz para apoyar su trabajo interpretativo: pañuelo, gafas, rosario y biblia (a los que no se alude en la versión escrita de 2001, pero que sí aparecen en la representación, sobre todo la última, para simbolizar acertadamente la trascendencia de la Biblia en la novela), junto a la toquilla, el termo y los mismos zapatos y las medias, auxilian a Lola Herrera en su actividad interpretativa quinésica y gestual e incluso en su movimiento, ocupación y posición en el espacio escénico, contribuyendo decisivamente a aliviar el enorme peso cualitativo y cuantitativo del lenguaje verbal durante todo el espectáculo.

La estructura de reducción temporal retrospectiva y rememorativa (Villanueva, 1977: 238) del discurso narrativo con respecto a la historia se mantiene asimismo en el relato escénico, que distribuye también cinco horas de la madrugada del día 24 de marzo de 1966 como tiempo de la historia, aunque incide de distintos modos en determinados aspectos del mismo en función del zeiterlebnis, de la vivencia subjetiva o personal del tiempo según el personaje (Pozuelo, 2004: 93-94), según Carmen.

Frente a las numerosas alusiones al tiempo en las secuencias inicial y final del discurso narrativo, en las representaciones, además de lo dicho en el parlamento de Carmen, son las luces las que simbólicamente significan este efecto. La contraposición de oscuridad, a veces con haz de luz sobre la actriz, e iluminación tiene un valor siempre sintático y/o enfatizador de la intimidad o relevancia de determinados pasajes: tres veces ocurre así en las representaciones durante el relato de Carmen, reduciéndose enormemente la luz al confesar sus dos encuentros con Paco y reflexionar sobre la Guerra Civil.

Pero normalmente, como indicábamos, la iluminación actúa como verdadero señalizador cronológico. El oscuro inicial, marcando la noche, se 
combina con un cañón que progresivamente resalta la enorme esquela que sobre un lienzo negro ocupa todo el escenario y se nos muestra mientras oímos la música primero y las voces de la gente que llena la escena inicial y prologal luego. La desaparición del lienzo deja muy brevemente a oscuras el escenario, indicando el cambio escénico, y tan solo dos haces de luz, uno primero enfocado al cabecero del ataúd y otro que después descubre a la actriz principal, resaltan el papel relevante y contrapuesto de estos dos elementos de la comunicación intraescénica. La iluminación cenital suave, simulando la de una estancia no demasiado iluminada, se mantiene a lo largo de toda la larga escena intermedia del soliloquio, salvo los tres cambios antes indicados. Tras un oscuro final y un haz de luz que resalta a Carmen arrojada sobre el ataúd, la nueva iluminación cenital de la escena epilogal en que entra el hijo representa el amanecer y el posterior apagón con dos focos marcando un plano de mitad de cada uno de los actores vuelve a dejar en suspenso el final y lanza al espectador los nuevos temores de Carmen con respecto a su hijo.

También los elementos musicales y sonoros contribuyen a señalar temporalidad y son idénticos en ambos montajes. La música de La mala muerte de Aute se oye al principio, coincidiendo con el cierre de la primera escena prologal, pero también al final, mientras baja el telón. No hay otros signos de este tipo a lo largo de toda la obra más que los señalados en las acotaciones de ambas versiones: el tarareo por Carmen de la canción $E l$ novio de la muerte y el sonido de cinco campanadas que indican la hora y avanzan el fin del monólogo pronunciado.

La gran cantidad de personajes intervinientes en el relato, unos como seres reales y otros como referencias en las palabras de Carmen, se ven enormemente reducidos aquí. Como en la novela, dos actores (Jorge de Juan/Pablo Rodríguez y Lola Herrera) representan a los dos únicos actuantes en la escena final y tan solo una es necesaria para cubrir dramáticamente el largo monólogo intermedio que ocupa casi toda la obra; el amplio número de personajes de la primera secuencia narrativa se sustituye por una serie de voces en off, que acertadamente simboliza funcionalmente lo que se pretende: ruidos de fondo, sólo gente.

Evidentemente, al margen del hijo que descubre a la madre finalmente que para su desgracia se parece a su padre en mucho más que el nombre, dos son los personajes primordiales; de ambos, a través del tejido de evocaciones que realiza Carmen, se realiza un amplio dibujo caracterológico en el que, con menor extensión y detenimiento en las adaptaciones que en la novela, se incide en su visión del amor, el dinero, el poder, el sexo, la autoridad, la caridad, el tiempo, la notoriedad, el dolor... de todos los temas generales que conciernen a y por los que son concernidos los seres humanos. Pero, además, determinados críticos han visto en ellos una capacidad representativa: Monleón (1979: 53), Sobejano (1981: 53-54), Morán 
(1982: 48-49), Neuschäfes (1985: 29-30) o González (2003: 53) coinciden globalmente al interpretar la obra como testimonio de una época y al observar en Carmen la encarnación de la pequeña burguesía miope y retrógrada de inicios del desarrollismo franquista y en Mario la del humanismo cristiano aperturista y el idealismo liberal crítico; esta lectura, con no ser inexacta ni mucho menos, es seguramente tanto más cierta cuanto más se piensa en la novela del 66 o la obra del 79, y acaso no tanto si se examina la adaptación de 2001, donde la actualización textual mediante supresiones y adiciones ha provocado que el funcionamiento simbólico de ambos, su tipización, pueda acercarse más a la de unos respectivos paradigmas sociales de lo avanzado y lo retrasado, de lo moderno y lo antiguo, o, si se quiere, de lo abierto y lo cerrado.

Pero en las representaciones, y como un factor clave del éxito de funcionamiento de la obra, hay que resaltar sobre todo, como ya ha hecho crítica y público, el trabajo interpretativo de Lola Herrera: la variedad de registros, inflexiones y tonos, incluyendo las distintas situaciones emotivas y las diversas interpelaciones al muerto, la perfecta enunciación del largo parlamento verbal, la capacidad individual de ocupación paulatina de todo el escenario, la gestualización y el acompañamiento con actos más secundarios (beber, colocarse las medias, ponerse las gafas, limpiar las sillas con un pañuelo...) o cardinales (mirar la biblia, lanzarse sobre el ataúd, confesar/negar su adulterio...), incluso el hecho de aguantar 80 minutos seguidos ante el espectador, en suma la maravillosa asimilación y estupenda interpretación del personaje.

En conclusión, pues. En este sucinto análisis de las relaciones entre las representaciones escénicas, las versiones dramáticas y la novela Cinco horas con Mario hemos observado los numerosos indicios de coincidencia en la historia de base y, también, en cambio, las grandes diferencias que se evidencian en el plano de la transgenerización, de la discursivización y del proceso comunicativo, mostrando así los lazos entre tres tipos de textos que han compartido cinco horas con Mario, pero siempre de diversa manera.

\section{REFERENCIAS BIBLIOGRÁFICAS}

A) Obras Estudiadas

Novela:

Delibes, M. (1966), Cinco horas con Mario, Barcelona, Destino, 2003 ${ }^{31}$.

Versiones teatrales:

Delibes, M., Paredes, S., SÁmano, J. y Molina, J. (1979), Cinco horas con Mario. Versión teatral, est. introduct. de G. SoBEJANO, Madrid, Espasa-Calpe, 1981, pp. 133191. 
Delibes, M., Molina, J. y SÁMAno, J. (2001), Cinco horas con Mario. Versión año 2001 (adaptación original inédita, 48 folios).

Representaciones teatrales:

Molina, J. (dir.) y Sámano, J. (prod.) (1979), Cinco horas con Mario. Versión teatral, con LOLA HERRERA y JORGE DE JUAN. Representación del 18/12/79 en el Teatro Marquina de Madrid.

Molina, J. (dir.) y SÁmANo, J. (prod.) (2001), Cinco horas con Mario, de Miguel Delibes, con Lola HERRERA y PABLO RODRÍGUEZ. Representación del 19/10/03 en el Teatro Real Cinema de Madrid.

B) OBRAS CONSULTADAS

Alvar, M. (1987), El mundo novelesco de Delibes, Madrid, Gredos.

Bajtín, M. (1929), Problemas de la poética de Dostoievski, México, F.C.E., 1986.

Beltrán Almería, L. (1992), Palabras transparentes, Madrid, Cátedra.

Bettetini, G. (1978), Producción significante y puesta en escena, Barcelona, Gustavo Gili.

Bobes, M. C. (1987), Semiología de la obra dramática, Madrid, Arco Libros (2. ${ }^{a}$ edic. correg. y aument.), 1997.

BREMOND, C. (1973), Logique du récit, Paris, Seuil.

BUCKLEY, R. (1973), Problemas formales de la novela española contemporánea, Madrid, Península.

Celma, P. (2003), «Introducción» a Miguel Delibes. Homenaje académico y literario, edic. de M. P. Celma, Valladolid, Universidad de Valladolid-Junta de Castilla y León, pp. 17-28.

ChATMAN, S. (1978), Historia y discurso. La estructura narrativa en la novela y en el cine, Madrid, Taurus, 1990.

CoHN, D. (1978), La transparence intérieur. Modes de représentation dans la vie psychique dans le roman, Paris, Seuil, 1981.

DOLEZEL, L. (1986), «Semiotics of Literary Communication», Strumenti Critici, 1, 1986, pp. 5-48.

Domínguez Caparrós, J. (2002), Teoría de la Literatura, Madrid, Centro de Estudios Ramón Areces.

Efe (10-9-03), «Lola Herrera vuelve a quedarse a solas 'cinco horas con Mario'», en noticias.ya.com/2003/09/10/5521868. html

El Mundo (4-12-01), «La actriz Lola Herrera estrena 'Cinco horas con Mario' en Girona», en www.elmundo.es/2001/12/04/catalunya/353097.html

Europa Press (18-03-02), «Manuel Galiana y Lola Herrera estrenan en Madrid la Trilogía Teatral Delibes», en www.planetadeagostini.es/noticias\&id $=129027 \& s=1$

Ferrero, J. (2003), «Lectura de 'Cinco horas con Mario'», en Miguel Delibes. Homenaje académico y literario,edic. de M. P. CELMA, Valladolid, Universidad de Valladolid-Junta de Castilla y León, pp. 154-160.

GARCÍA BARRIENTOS, J. L. (1991), Drama y tiempo, Madrid, CSIC.

GARRIDO GALlARDo, M. A. (2000), Nueva introducción a la teoría de la literatura, Madrid, Síntesis.

GENETTE, G. (1972), Figuras. III, Barcelona, Lumen, 1991.

- (1982), Palimpsestos. La literatura en segundo grado, Madrid, Taurus, 1989.

GonzÁleZ, J. R. (2003), «Miguel Delibes: los caminos de un novelista», en Miguel Delibes. Homenaje académico y literario, edic. de M. P. CELMA, Valladolid, Universidad de Valladolid-Junta de Castilla y León, pp. 43-60. 
Gullón, A. (1980), «Ecos de las sentencias de ayer: 'Cinco horas con Mario'», en La novela experimental de Miguel Delibes, Madrid, Taurus, pp. 47-67.

Gullón, G. y A. (eds.) (1974), Teoría de la novela (Aproximaciones hispánicas), Madrid, Taurus.

LóPeZ MaRTíneZ, L. (1973), La novelística de Miguel Delibes, Murcia, Universidad de Murcia.

Medina-Bocos, A. (1987), Cinco horas con Mario, de Miguel Delibes, Madrid, Alhambra.

Monleón, J. (1979), «Cinco horas con Mario, al teatro. La pequeña burguesía del franquismo», Triunfo, 880, 8-12-79, p. 53.

Montero, I. (1968), "'Cinco horas con Mario': el lenguaje del limbo», Revista de Occidente, 61, abril, pp. 101-117.

MORÁN, F. (1982), «Personajes femeninos en la novela española», en La destrucción del lenguaje y otros ensayos literarios, Madrid, Mezquita.

NEUSCHÄFES, M. y H-J. (1985), “'Cinco horas con Mario'. Veinte años después. Y desde fuera», Cuadernos del Norte, 34, nov.-dic., pp. 24-31.

Pavis, P. (1980), Diccionario de teatro. Dramaturgia, estética, semiología, Barcelona, Paidós, 1983.

PozUelo, J. M. ${ }^{a}$ (2004), Ventanas de la ficción. Narrativa hispánica, siglos XX y XXI, Barcelona, Península.

REY, A. (1975), La originalidad novelística de Delibes, Santiago, Universidad de Santiago.

SanZ VillanueVA, S. (1980), Historia de la novela social española (1942-1975), II, Madrid, Alhambra.

SCHMIDT, S. J. (1980), Fundamentos de la ciencia empírica de la literatura. El ámbito de actuación social de la literatura, Madrid, Taurus, 1990.

Sobejano, G. (1981), «Estudio introductorio» a Cinco horas con Mario. Versión teatral, Madrid, Espasa-Calpe, 1981, pp. 9-132.

TALENS, J. (1986), El ojo tachado. Lectura de «Un chien andalou» de Luis Buñuel, Madrid, Cátedra.

VALLES, J. (1999), El espacio en la novela. El papel del espacio narrativo en «La ciudad de los prodigios» de Eduardo Mendoza, Almería, Universidad.

- y Álamo, F. (2002), Diccionario de Teoría de la Narrativa, Granada, Alhulia.

VeGa MARTín, C. (1995), Novela y teatro en Miguel Delibes: un estudio comparativo ("La hoja roja», "Cinco horas con Mario» y "Las guerras de nuestros antepasados»), Málaga (Tesis Doctoral)

VillanueVA, D. (1977), «Miguel Delibes: de 'El camino' (1950) a 'Cinco horas con Mario' (1966)», en Estructura y tiempo reducido en la novela, Valencia, Bello, pp. 238-247. 
JOSÉ R. VALLES CALATRAVA

\title{
RESUMEN
}

Del papel a las tablas: el proceso transductivo de Cinco horas con Mario de Delibes (novela, versiones, representaciones teatrales), por José R. Valles Calatrava.

La finalidad de este artículo consiste en realizar un análisis comparativo entre la novela de Miguel Delibes Cinco horas con Mario, sus dos versiones dramáticas realizadas en 1979 y 2001 y dos de las representaciones teatrales basadas en las anteriores y efectuadas en 1979 y 2003 . Metodológicamente, se examinan primero las potencialidades teatrales o valores de «adaptabilidad» de la novela; se estudian después las alteraciones textuales generadas con respecto a la obra narrativa por las dos versiones dramáticas, así como sus similitudes y diferencias internas; se acaban analizando por último las especificidades tanto comunicativas como escénicas aportadas por las citadas representaciones teatrales frente a sus distintos antetextos escritos.

Palabras clave: Literatura española contemporánea, Novela, Narrativa, Teatro, Dramatización, Adaptación, Transducción.

\begin{abstract}
:
The main objective of this article takes the task of carrying out a comparative analysis between the novel Cinco horas con Mario by Miguel Delibes, two drama script versions written in 1979 and 2001 and finally two theatrical plays based in the previous ones and performed in 1979 and 2003. From a methodological point of view, we first take into consideration the dramatic potential or adaptability of the novel. We then study the text changes implemented to the two drama versions in comparison with novel, as well as the internal similarities and differences. Lastly, we analyze the specifics in communication and performance of the theatrical plays, comparing them to their respective previous written texts.
\end{abstract}

Words key: Contemporary Spanish Literature, Novel, Narrative, Theatre, Dramatization, Adaptation, Transduction. 